\title{
MORPHOMETRIC IDENTIFICATION OF STEM BORERS Diatraea saccharalis AND Diatraea busckella (Lepidoptera: Crambidae) IN SUGARCANE CROPS (Saccharum officinarum) IN CALDAS DEPARTMENT, COLOMBIA.
}

Julián Andrés Valencia Arbeláez ${ }^{1 \uparrow^{* * a}}$, Alberto Soto Giraldo ${ }^{1 \&}$, Gabriel Jaime Castaño Villa $^{3 \&}$, Luis Fernando Vallejo Espinosa ${ }^{1 \&}$, Melba Ruth Salazar Guitierrez ${ }^{4 \&}$

${ }^{1}$ Agricultural Engineering Faculty, University of Caldas, Manizales, Caldas Colombia

${ }^{2}$ Department of Natural Sciences, University of Caldas, Manizales, Caldas Colombia

${ }^{3}$ AgweatherNet, Washington State University, Prosser, Washington, USA

\#a Current Address: ${ }^{1}$ Agricultural Engineering Faculty, University of Caldas, Manizales, Caldas Colombia

* Corresponding author

E-mail: julianandres.valenciaarbelaez@gmail.com

${ }^{\&}$ These authors also contributed equally to this work 


\section{Abstract}

The sugarcane (Saccharum sp. ), of great importance for being one of the most traditional rural agroindustries in Latin America and the Caribbean, as part of the agricultural systems, is vulnerable to increases or reductions in the incidence of pests associated with extreme events of climate change, such as prolonged droughts, hurricanes, heavy and out of season rains, among others, contributing to the increase losses in agricultural production , which forces farmers to make excessive expenditures on pesticides that generally fail to solve the issue. (Vázquez, 2011). The main pest belongs to the Diatraea complex (Vargas et al., 2013; Gallego et al., 1996), a larval stage perforator habit. Different field evaluations have revealed the presence of a species that had not been reported in sugarcane crops, Diatraea busckella, and to corroborate the finding, a method of identification was needed whose advantage was to be quick and also low cost, in this sense, geometric morphometry is a mathematical tool with biological basis (Bookstein, 1991), which allows to decompose the variation resulting from the physiology of individuals of the most stable individuals of the population, product of the genetic component. CLIC (Collecting Landmarks for Identification and Characterization) was used for identification, with reference to the previous right wing (De La Riva et al., 2001; Belen et al., 2004; Schachter-Broide et al., 2004; Dvorak et al., 2006; Soto Vivas et al., 2007). Wing morphometry was performed using generalized Procrustes analysis (Rohlf and Marcus, 1993). The analysis clearly differentiated between $D$. busckella and $D$. saccharalis, eliminating the environmental factors that could generate some level of error, being considered a support tool that validates the molecular biology processes for the identification of organisms. 
Keywords: Landmarks, Procrustes, Main component analysis, Wings.

\section{Introduction}

Recent studies have highlighted the vulnerability of agriculture to climate variables and the effects on harvests of pests and diseases (Lau et al., 2011; Carvajal, 2010; Contreras and Galindo, 2009). Within this context, in agricultural systems, it has been possible to verify increases or reductions in the incidence of pests associated with extreme events of climate change, such as prolonged droughts, hurricanes, heavy and out of season rains, among others. Of course, these are often not measurable, because the disasters caused by such events in crops do not allow us to appreciate the changes in the manifestations of pests. However, these contribute to increased losses, forcing farmers to spend too much on pesticides that usually fail to solve the problem. (Vázquez, 2011).

A crop that is not exempt from these changes of climatic variability is the sugarcane (Saccharum sp.), of great importance for being one of the most traditional rural agroindustries in Latin America and the Caribbean and whose world production is around 13 million tons per year (FAO, 2007). In order of importance, the first country to produce sugarcane is India, followed by Colombia, where it is the second largest source of rural economic production after coffee (CENICAÑA, 2007; DANE, 2007; FAO, 2007). As with all agricultural holding, sugarcane crop is no stranger to pest attacks, with the main impact being the borers of the Diatraea complex (Vargas et al., 2013; Gallego et al., 2007), 1996), and its permanent presence in the larval stages and its permanent presence either in the mouths or in new crops, 
causes from damage to the bud in the initial stages of the crop, to perforations in the nodes or internodes causing the plant to tip over and loss in quality due to loss of sucrose (Parody, 2011; Gallego et al., 1996).

However, numerous studies in different aspects of biology are being carried out, which seek to understand the origin, nature and causes of change in variation patterns, with the aim of finding answers to the integrated management of the insect and control methods, using quantitative analyses of phenotypic variation and its relationship with the environment, genetics and random factors (or of unknown origin), necessary to identify organisms (Jaramillo, 2011).

These insects, like all living organisms, visibly highlight their morphological variability. A number of biological and non-biological factors underlie such variability by interacting in a complex way to model individuals, populations and species (Calle, 2008).

Although the size and colour of larvae and adults are characteristics that, in a very approximate way, allow us to distinguish species of the Diatraea spp complex with a relatively low margin of error, more precise and state-specific characteristics are required to identify the species with a high degree of precision (Gómez et al., 2014), which is why we mainly use external morphological and genitalia characteristics (Cadena, 2008; Linares and Bastidas, 1996). 
These biological factors are the product of micro- and macro-evolutionary processes interacting with the environment. Thus, the size and morphological conformation results from the interaction between maternal effects and quality of life during development with the genotypic combinations inherited from the parents, within a genetic framework given by evolutionary history. The populations and species, then, acquire their own morphological features that have a differential impact on their biology and ecology (Jaramillo, 2011). Evidence of these factors was found in late 2012, near the town of Cartago, Valle del Cauca, Colombia, where Diatraea larvae were collected that apparently did not match the characteristics of $D$. saccharalis and D. indigenella. Morphological observation of the different stages of life (larva, pupa and adult) allowed the identification of the larvae belonging to the species Diatraea busckella, with the initial records of this species attacking sugarcane crops. (Vargas et al., 2013).

To corroborate that, a identification method was needed that was both quick and costeffective. In this sense, geometric morphometry is a mathematical tool with biological grounds (Bookstein, 1991), which allows us to decompose the variation resulting from the physiology of the individuals of the most stable individuals in the population, a product of the genetic component. It allows the identification of individuals from the conformation of specific structures, in closely related species (Dujardin, 2000), based on methods of description and statistical analysis of the form variation in particular structures within and between individuals (Rohlf and Marcus, 1993). This technique has been used in various types of plant and animal organisms (vertebrates and invertebrates), and particularly in insects of agricultural and medical importance, such as Nymphalidae, Tortricidae, Noctuidae 
,Triatominae, and Culicidae. It has been used in studies of population structure (De La Riva et al., 2001; Belen et al., 2004; Schachter-Broide et al., 2004; Dvorak et al., 2006; Soto Vivas et al., 2007), species identification (Matías et al., 2001; Villegas et al., 2002; Calle et al., 2008), to detect differences between field parents and laboratory descendants (Jaramillo and Wolff, 2002), as well as in phylogenetic studies (Soto Vivas et al., 2011).

Quantifying and analyzing the morphological variation resulting from such interactions is the main objective of morphometry. (Jaramillo, 2011), in addition, there is little research work on aspects of insect identification, particularly related to the use of morphometry.

\section{Materials and methods}

The collections were carried out in 4 sugarcane municipalities in the department of Caldas, Colombia (Table 1) every two weeks in 120 randomly selected points (canes), making a 40 minutes zigzag trip per plot within the cane crops, following the orientation according to the linear distribution of the "chorrillo" (Pérez et al., 2011), or at the time of cutting in the sugarcane mills where samples of eggs, larvae, pupae and adults were taken, from the time when the first true leaves appear in the crop of sugarcane until the time of harvest. The larval collections were manual in each of the sampled sites, in order to obtain the infestation index, recorded as the location of the collection points, so that a representative sampling of the area can be obtained. 
Table 1. Geographical location of collection points for D. busckella and D. saccharalis.

N: North, W: West

\begin{tabular}{|c|cc|}
\hline Town & $\mathbf{N}$ & $\mathbf{W}$ \\
\hline Riosucio & $05^{\circ} 28,501^{\prime}$ & $75^{\circ} 40,844^{\prime}$ \\
Supía & $05^{\circ} 26,644^{\prime}$ & $75^{\circ} 40,010^{\prime}$ \\
Filadelfia & $05^{\circ} 18,34^{\prime}$ & $75^{\circ} 33,609^{\prime}$ \\
Neira & $05^{\circ} 12,484^{\prime}$ & $75^{\circ} 33,105^{\prime}$ \\
& $05^{\circ} 16,099^{\prime}$ & $75^{\circ} 4,617^{\prime}$ \\
\hline
\end{tabular}

Each individual collected in the larval stage, was taken to adult, under controlled conditions of temperature $\left(20 ; 24.7\right.$ and $\left.30^{\circ} \mathrm{C}\right)$ and relative humidity $(35 \%)$, using a diet of sweet corn not exceeding 30 days, in the Center for Research and Breeding of Natural Enemies, located in the botanical garden of the University of Caldas at $5^{\circ} 3^{\prime} 23^{\prime \prime \prime}$ latitude north and $75^{\circ} 29^{\prime} 39^{\prime \prime \prime}$ west longitude, at an altitude of 2160 meters above sea level and with an average temperature of $14^{\circ} \mathrm{C}$ (Manizales, Caldas).

In order to identify which species are present within each evaluated site, the external morphology of the right rear wing was characterized in an adult state from the junction of the basal portion articulated to the thorax. (Jaramillo, 2011; Cadena, 2008; Pastrana, 1991). 
To assemble the wings, the scales were first removed by washing with $10 \% \mathrm{NaClO}$ for 5 minutes, then rinsed with distilled water for another 5 minutes. The wings were mounted on slide film and for their preservation clear varnish was used and the images were taken from a Nikon SMZ1270 stereoscope at a 1. 5x zoom.

On the wing images, twenty-four (24) points were selected between the limits of the basal and subcostal veins and the intersections of the $\mathrm{Cu} 1$ and 2 veins with the distal edge of the wing (Fig 1 and Fig 2). These points allowed the geometric configuration of each wing to be captured (Calle et al., 2008).

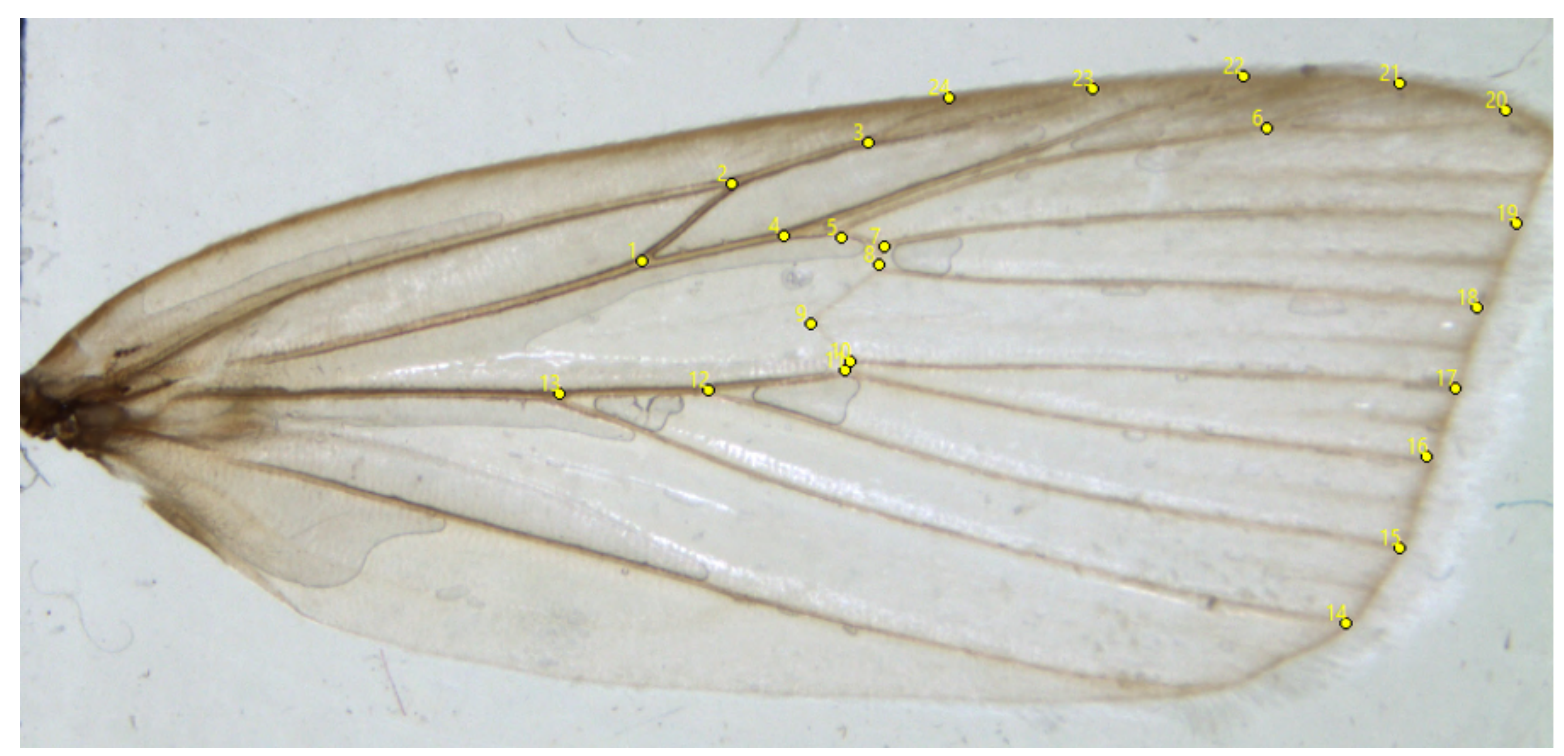

Fig 1. Right rear wing of $\boldsymbol{D}$. busckella. Landmarks for identification of morphometric points. 


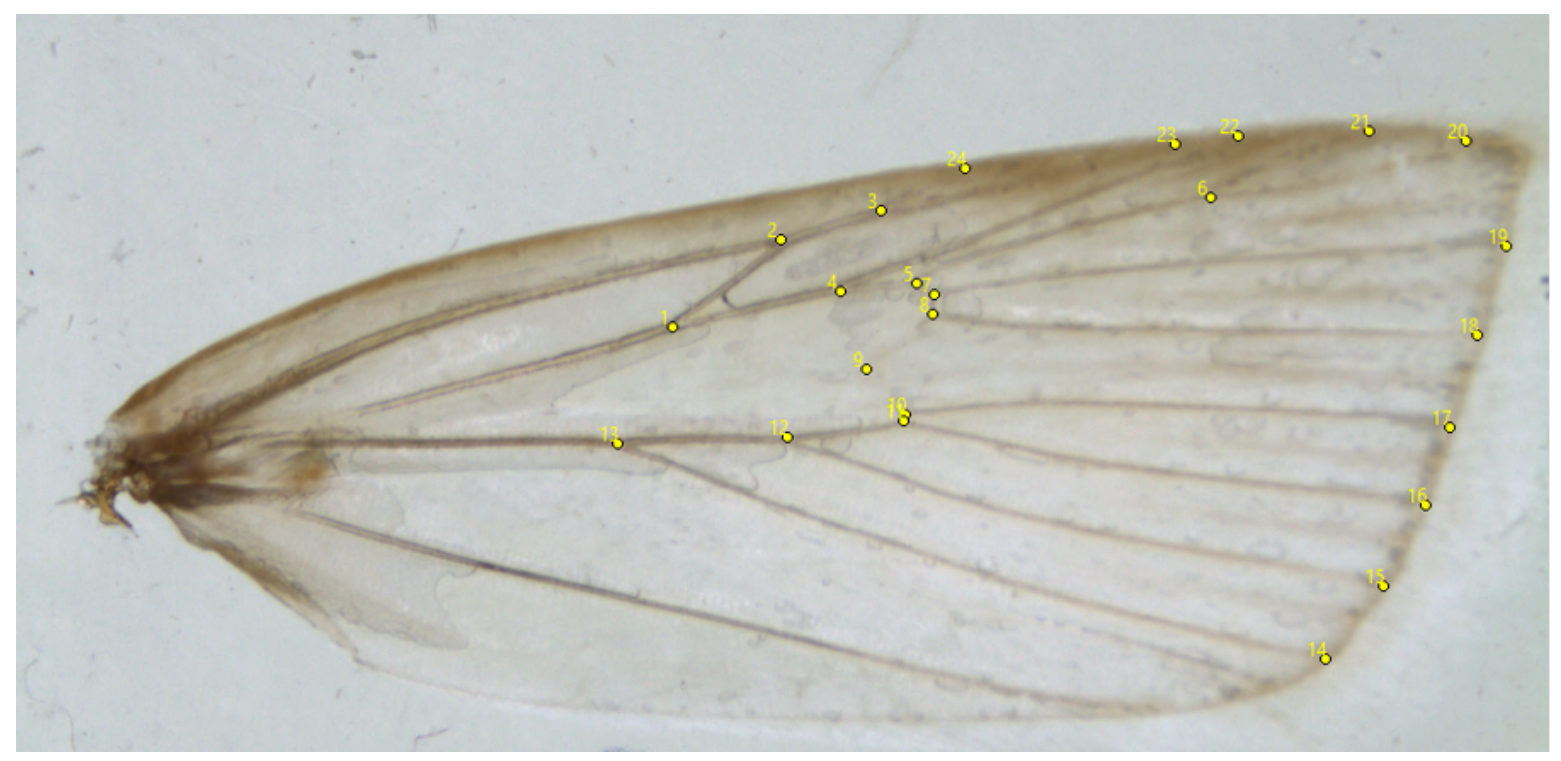

Fig 2. Right rear wing of $\boldsymbol{D}$. saccharalis. Landmarks for identification of morphometric points.

CLIC (Collecting Landmarks for Identification and Characterization) open access software (mome-clic. com) was used for identification, taking as a reference the previous right wing, based on similar research for different arthropods (De La Riva et al., 2001; Belen et al., 2004; Schachter-Broide et al., 2004; Dvorak et al., 2006; Soto Vivas et al., 2007).

Wing morphometry was performed using generalized Procrustes analysis (Rohlf. And Marcus, 1993; The anatomical reference points were chosen taking into account their easy identification and reproducibility, hence, that they have homology of position among the individuals in the stock (Bookstein, 1991). 24 anatomical reference points were selected. According to their categories (Bookstein, 1991), on the wings all anatomical reference points are type 1 . 
The geometric configuration of the wings was obtained by capturing the points at the intersections of the radial (R2 and R3), medial (M2 and M3) and cubital ( $\mathrm{Cu} 1$ and $\mathrm{Cu} 2)$ veins, with the distal borders: R5, M1, M2, M3, Cu1 and $\mathrm{Cu} 2$. (Figures 3 and 4). Based on the Bookstein classification, 1991, all APRs (Anatomical Position of the Reference points) were type I, representing vein-to-vein intersections and vein completion at the wing border (Bookstein, 1991).

Thereafter, isometric size was eliminated and morphological conformation variables were created to evaluate the relative amounts of variation between individuals, the value of asymmetry (if both sides of the specimens have been measured) and measurement error.

For the repeatability estimation (R), corresponding to two repeated measurements of the same points on 30 randomly selected images. R provides a proportion of the variance between measurements, individuals and the total variance (Henry et al., 2010).

The input file should contain the two successive measurements of exactly the same individuals in exactly the same order, indicating the extent to which two measurements of the same individual are correlated. To decrease the error level, 1000 permutations were run. Coordinates with high repeatability were used for the analysis. The repeatability tests were carried out using the VARwin program developed by Jean Pierre Dujardin (IRD. Montpellier, France) and freely available on the Internet at http://www. mpl. ird. fr/morphometrics/). 


\section{Results and discussion}

The 24 reference morphometric points allow to differentiate $D$. saccharalis and $D$. busckella. With distances of X from -0.304 to 0.275 and $\mathrm{Y}$ between -0.122 to 0.222 , where both species can be separated only by generalized analysis of Procrustes (Fig 3).

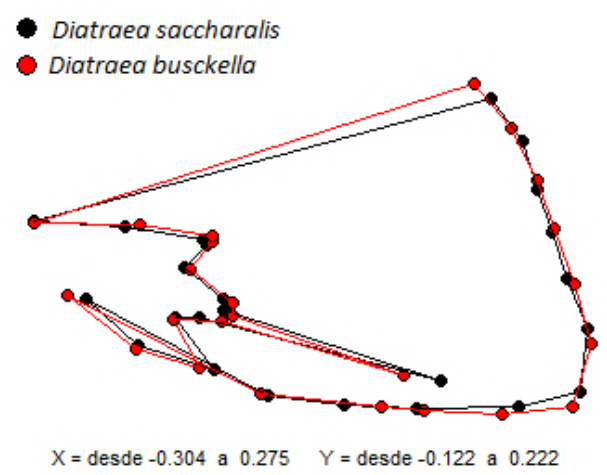

Fig 3. Distances and formation of 24 morphometric points for $D$. saccharalis and $\boldsymbol{D}$. busckella.

\section{Repeatability analysis:}

The repeated measurements twice in order to decrease the level of error, showed an excellent relationship both in the centroid size $(\mathrm{df}=0.91$ between species and 0.45 between groups), and in the aligned landmarks after generalized analysis of Procrustes, being higher than 0.9 between species (table 2). The repeatability in this case was 0.066 , indicating a large separation between the groups evaluated. In relation to the permutations, no greater distance was found in the ratio $0 / 1000(0.000)$. 
Table 2. Generalized Procrustes analysis

\begin{tabular}{|c|c|c|}
\hline Procrustes & Between species & Within groups \\
\hline SS & 0,04 & 0,01 \\
\hline $\mathbf{d f}^{*}$ & 1,39 & 0,68 \\
\hline MS & 0,06 & 0,01 \\
\hline
\end{tabular}

At the time of the simple Re-classification, the classified individuals who were part of the discriminant analysis, presented a correct assignment, where D. saccharalis: 50 / 50 (100\%) D. busckella: 50 / 50 (100\%), as second verifier, was used the Cross Classification where D. saccharalis: 50 / $50(100 \%)$ and D. busckella: 50 / 50 (100\%), indicating that the location of the morphometric points and wings are within the correct group.

\section{Size}

Both in the aggregate sample of 50 D. saccharalis and 50 D. busckella in each range of factors assessed, the difference between species in size was evident: D. busckella is significantly larger than $D$. saccharalis. The centroid size of the size variation by species was obtained as quartile graphs. Each box shows the median and quartiles 10 and 90 . Below each box, the blue lines show the distribution of individuals according to their size. The units are pixels converted to millimeters, where the Mean and type of interval was 53,$109 ; 4,071$ respectively (Fig 7). 


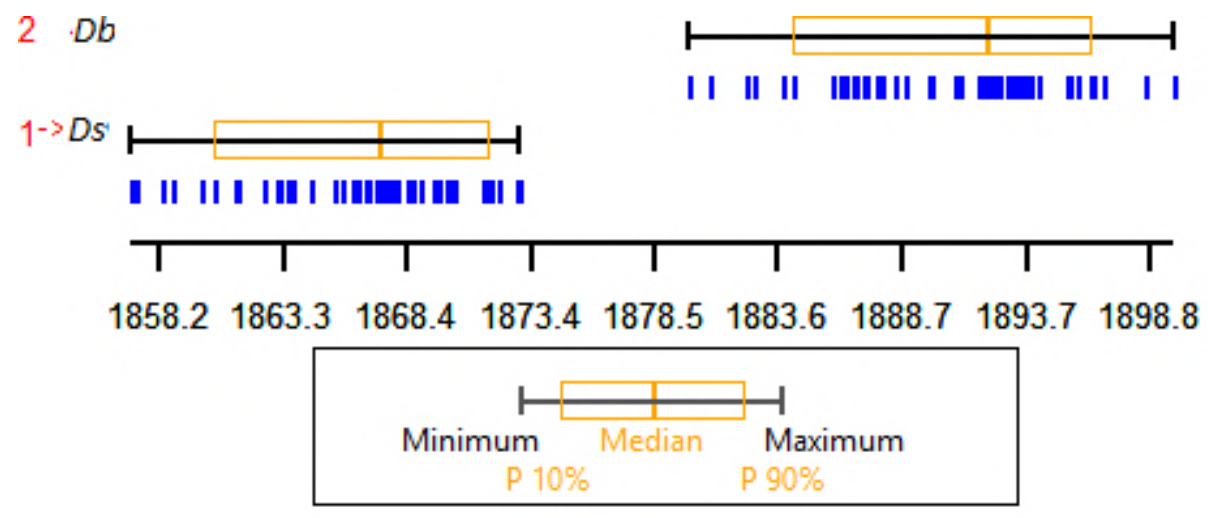

Fig 4. Centroid size for Diatraea busckella and Diatraea saccharalis.

The Principal Components Analysis showed two large conglomerates according to wing shape (Fig 5). The first conglomerate was made up of D. saccharalis and D. busckella, where the contribution was PC1 0. 999997360 and PC2 0. 999998647.

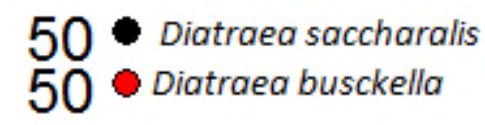

$P C A X=P C 1, Y=P C 2$

Fig 5. Principal component analysis. $D$. busckella and $D$. saccharalis for 50 individuals of each species.

\section{Alometry}


In both species the alometry was highly significant $(p<0.0001)$. However, when the size of the individuals was removed, the wing conformation continued to be different, the alometric slopes were in the same direction (Wilks $=0.001 ; \mathrm{df}=98 ; \mathrm{r}=25 \%$ ), i. e., the differences in conformation were not due to a size intervention, the conformation was free of alometry $(p=0$. 000) (Fig 6). However, when correcting the influence of size on the conformation coordinates, through the model of alometric slopes, the variability of shaping lingered $(p<0.0001)$, considering that the difference between species in conformation was free of size, these variations found can be caused by evolutionary divergence processes, more related to its acquis $(\mathrm{r}=45 \%, \mathrm{df}=98)($ Fig 7$)$.

The Mahalanobis distances calculated between each pair of species were all significant (53. 56) when evaluating the null hypothesis by 1,000 permutations; showing that the 2 species collected in the different regions of Caldas are different and that these results are not random products. In addition, the centroids (multivariate conformation means) of each entity allow the species to be clearly differentiated. This demonstrates the importance of the conformation of the wing to separate the species of the genus Diatraea.

In S. frugiperda Individuals differed significantly in the size and shape of their wings, and therefore in the geometric shape of their wings. Morphometry represents a promising tool for recognizing specimens of each strain of specimen collected in the field (Cañas et al., 2016). 


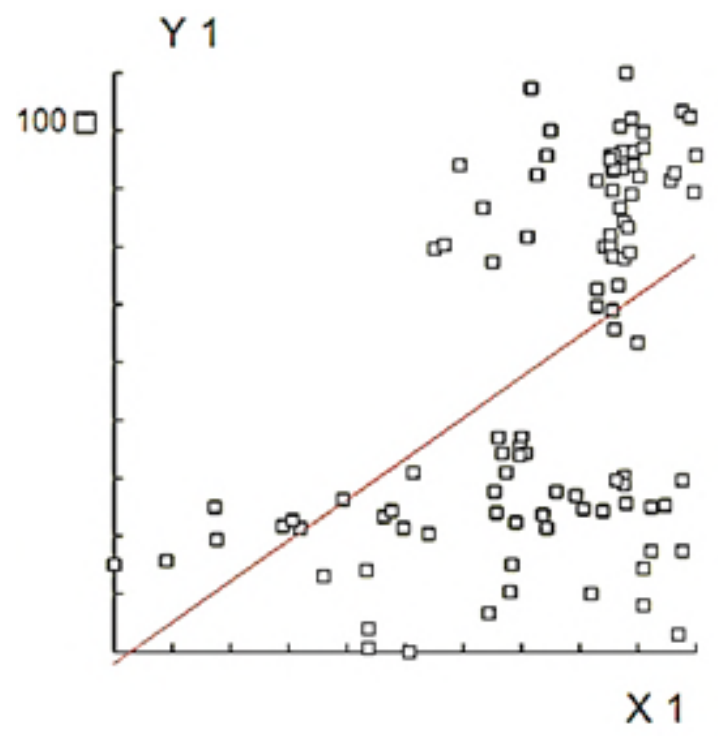

Fig 6. Differences in conformation without size intervention for $D$. busckella and $D$.

saccharalis.

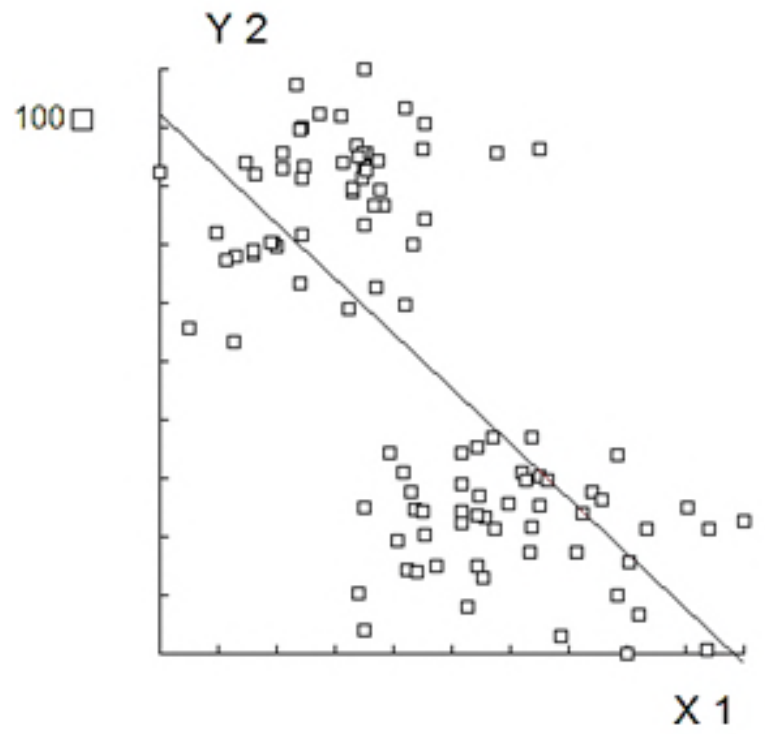

Fig 7.Correction of size influence on the conformation coordinates for $D$. busckella and $D$. saccharalis. 


\section{Relative wing deformations.}

The differences in wing shape were displayed on the deformation grids. The direction of the APRs movements was opposite between D. saccharalis and D. busckella. In both species the vectors of APRs 4-5, 12-13 and 6 were directed towards the center of the wing border, the arrows of APRs 14,15 and 16 were directed towards the edge of the costal vein, the vector of PAR 19 upwards and the vectors of APRs 17 and 18 downwards along the border of the wing, showing a tendency to widen in the APRs located at the border of the wing (Fig 8).
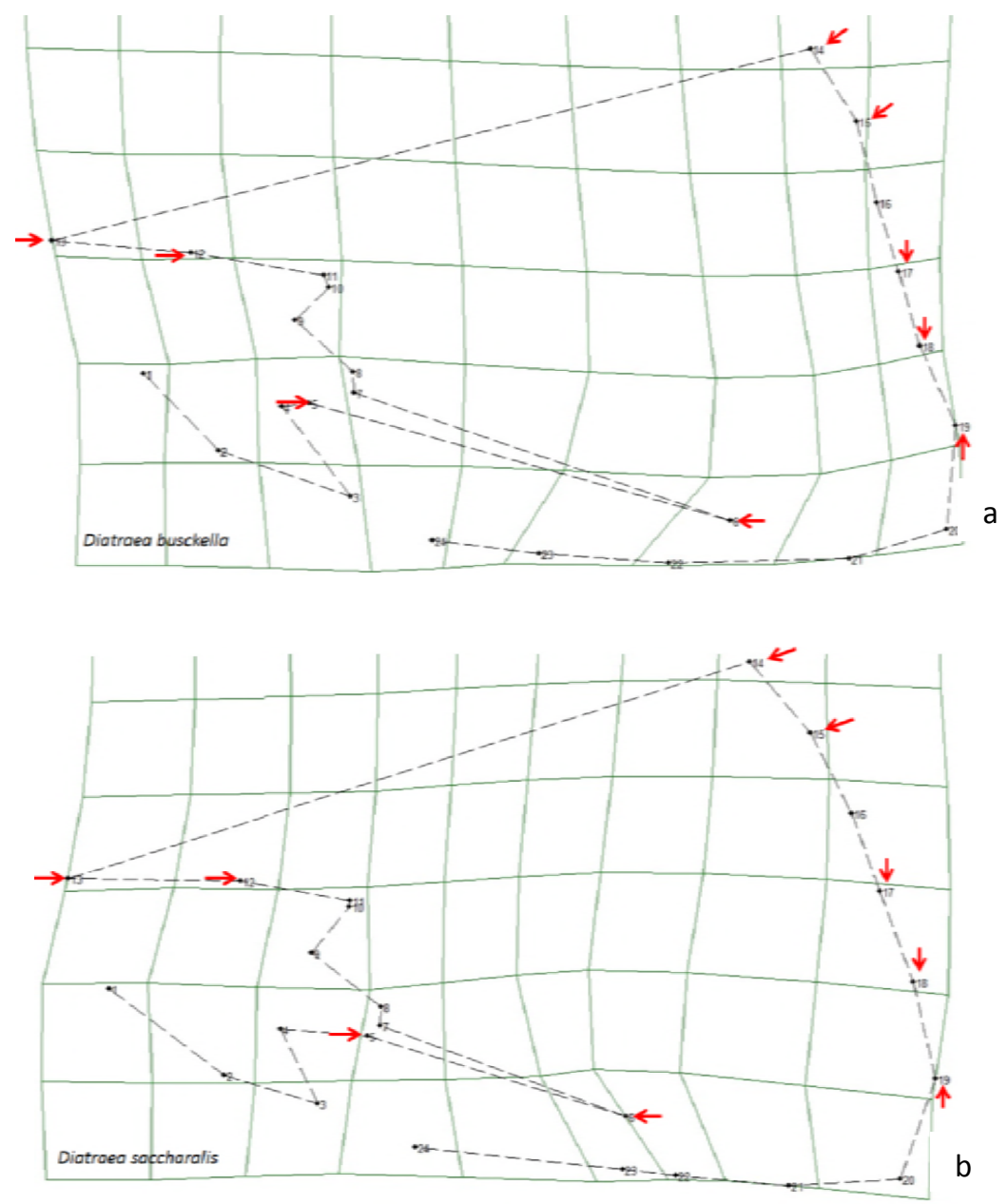
Fig 8. Relative wing deformation for a) Diatraea busckella and b) Diatraea saccharalis.

The contrast between D. saccharalis and D. busckella in size and conformation could be confirmed. In Diatraea spp the difference in size had been detected in pupae and adult states (Betts y Wootton,1988; Calle et al., 2008; Cadena, 2008; De Vries et al., 2010). However, the divergence in the wings may provide information about possible environmental and genetic pressures that species are suffering (Dellicour et al., 2017). Several studies show that the difference between size and habits can influence the life history traits of insects (Cadena, 2008).

Size: Wing size is usually associated with the size of the insect's body (Dujardin, 2008; Francuski. et al., 2009). In the size of D. saccharalis and D. busckella, the difference was striking, D. busckella was larger than D. saccharalis $(\mathrm{p}<0.0001)$. This trend is very common in butterflies, moths, and other insects (Adams \& Funk, 1997; Hernández et al. 2010; Henry et al. 2010, Sontigun et al., 2017), several authors agree that they reflect different selection pressures according to the species (Ayala et al, 2011; Sontigun et al, 2017). The larger size may be favored by natural selection in the case of females to increase fecundity, suitability and lifespan (Hernández, et al. 2010, Francuski, et al., 2009, Adams \& Funk, 1997). Whereas the small size of the male may be the result of sexual selection because of the rapid development that leads to early hatching (Hernández et al. 2010). In D. saccharalis and D. busckella there is no work to support this statement, in females the dynamics of the species 
have not been measured in terms of size, but in males if early hatching has been observed with respect to females (Baena, 2010).

\section{Conformation}

The difference of Diatraea spp was highly significant $(\mathrm{p}<0$. 0001) (Fig 9). Wing conformation may be affected by the two types of selection: 1) Natural, which is related to flight ability; (Francuski et al., 2009; Gidaszewski et al., 2009; Hernández et al., 2010), 2) sexual, related to differences in reproductive roles between males and females (Marsteller et al., 2009). The function in relation to flight habits and distances travelled is an important mechanism of isolation between species and wing shape can be a response to life traits and histories, this selection pressure can accelerate evolution and is associated with speciation of various groups (Andersson, 1994; Marsteller et al., 2009).

In D. busckella an elongation of the wing was noted (Figure 12), this tendency may be related to the periods of flight required to oviposit or find the female sexually active (Hernández et al., 2010; Dellicour et al., 2017). A longer wing reduces energy requirements, breaks frictional forces and improves aerodynamic drag, giving greater dispersion ability required for long flight periods (Wotton, 1992; Betts and Wootton, 1988; DeVries et al., 2010; Shi et al., 2015). 
In the aggregate sample, the difference in the conformation of the wings D. busckella and $D$. saccharalis was highly significant (Wilks $=0.57, \mathrm{df}=99 \mathrm{p}<0.0001$ ). As there was no overlap between the species and according to the validated Landis and Koch classification, the concordance of the reclassification was perfect (Landis \& Koch, 1977; Ayala et al., 2011).

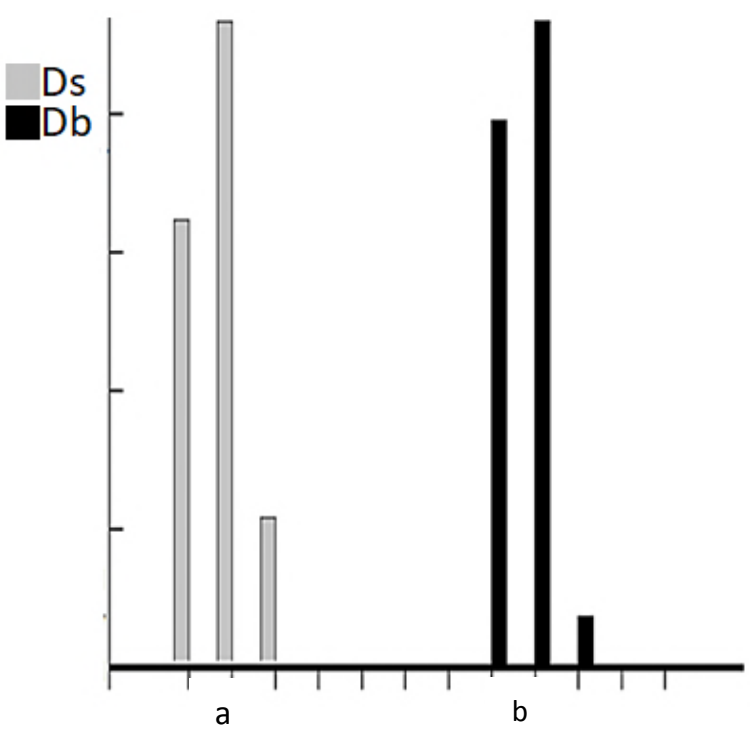

Fig 9. Individuals grouped by species a). D. saccharalis in white, b). D. busckella in black) along the discriminant axis.

\section{Conclusions}

Morphometric tools have proven their usefulness in the discrimination of arthropods, particularly in vector insects that cannot be identified by traditional morphological characteristics, as well as in studies of intra-specfic variability (Dujardin et al., 1997, 1998; Rubiio-Pallis, 1998; calle et al., 2002, 2008; Sontigun 2017). 
Geometric morphometry, describing the changes in shape from the separation of its most important components (size and configuration), open an innumerable possibilities for the performance of inter and intra-specific analyses, as well as for application in areas such as taxonomy, systematics, biomechanics, ethology and ecology (Becharia and Liria, 2012).

The shape of the wings can be a useful tool to separate the taxa at the genus and species level depending on the taxa analyzed. It can be highly reliable, especially for classifying Diatraea species. Alometry did not affect species separation (Sontigun et al., 2017).

In the present study, the importance of using geometric morphometry is noted. By including the anatomical points that defined the geometric configuration of the wing, the conformation of each species was obtained, and they were separated from each other with a high degree of confidence. In addition, it was possible to visualize the differences in wing shape between the species.

The use of geometric morphometry clearly differentiated between D. busckella and $D$. saccharalis, eliminating the environmental factors that could generate some level of error, being considered a support tool that validates the molecular biology processes for the identification of organisms. 
It was corroborated that the presence of D. busckella is clear in the department of Caldas, and is in greater proportion than D. saccharalis, being possible the colonization of this species by the effect of global warming, it is recommended to carry out work to validate this hypothesis.

\section{Acknowledgements}

To the National Sugar Cane Center of Colombia CENICAÑA for its valuable contribution and collaboration in the supply, development and analysis of information.

To Research Center for Research, Innovation and Technology to the Sugarcane Sector of the Caldas Department BEKDAU, for contributing significantly to the development and execution of the project.

To Washington State University WSU, for guiding me in the development and analysis of each of the parameters evaluated

\section{References}

1. Ayala, D; Caro-Riaño, H; Dujardin, JP; Nil Rahola, N; Simard, F; Fontenille, D. 2011. Chromosomal and environmental determinants of morphometric variation in natural populations of the malaria vector Anopheles funestus in Cameroon. Infection, Genetics and Evolution 11: 940-947. 
2. Becharia, W; Liria, J. 2012. Morfometría geométrica en cinco especies de Buthidae y Scorpionidae (Arachnida: Scorpiones) de Venezuela. Revista Mexicana de Biodiversidad 83: 421-431

3. Belen, A; Alten, B; Aytekin, AM. 2004. Altitudinal variation in morphometric and molecular characteristics of Phlebotomus papatasi populations. Med. Vet. Entomol. 18: $343-350$.

4. Betts, C; Wootton, R. 1988. Wing shape and flight behaviour in butterflies (Lepidoptera: Papilionoidea and Hesperioidea): A preliminary analysis. J. Exp. Biol. 138: $271-288$.

5. Bookstein, FL. 1991. Morphometric tools for landmark data: Geometry and Biology. Cambridge, EEUU.

6. Calle, DA; Quiñónez, M; Erazo, H; Jaramillo, N. 2008. Discriminación por morfometría geométrica de once especies de Anopheles (Nyssorhynchus) presentes en Colombia. Biomedica 28: 371-385.

7. Cadena, P. 2008. Caracterización morfológica y molecular de especies de Diatraea spp (Lepidóptera: Crambidae). P31. Informe final. Cali. COLCIENCIAS CENICAÑA.

8. Cañas-Hoyos, N; Márquez, EJ; Saldamando-Benjumea, CI. 2011. Heritability of Wing Size and Shape of the Rice and Corn Strains of Spodoptera frugiperda (J.E. Smith) (Lepidoptera: Noctuidae). Neotropical Entomology DOI 10.1007/s13744016-0393-y.

9. Carvajal, Y. 2010. Efectos de la variabilidad climática y el cambio climático en la agricultura. Estrategias de mitigación y adaptación para el sector. Revista Memorias, vol. 8, núm. 14, pp. 85-102. 
10. Contreras, SC; Galindo, MG. 2009. Implicaciones y consecuencias del cambio climático. Universitarios Potosinos. Año 5, número 6. UASLP. p. 4-9.

11. De La Riva, J; Le Pont, JF; Ali, V; Matias, A; Mollinedo, S; Dujardin, JP. 2001. Wing Geometry as a tool for studying the Lutzomyia longipalpis (Diptera: Psychodidae). Mem. Inst. Oswaldo Cruz 96: 1089-1094.

12. Dellicour, S; Gerard, M; Prunier, JG; Dewulf, A; Kuhlmann, M; Michez, D. 2017. Distribution and predictors of wing shape and size variability in three sister species of solitary bees. PLoS ONE 12 (3): e0173109.

13. DeVries, PJ; Penz, CM; Hill, R. 2010. Vertical distribution, flight behaviour and evolution of wing morphology in Morpho butterflies. J. Anim. Ecol. 79: 1077-1085.

14. Dujardin, JP. 2000. Introducción a la Morfometría, con énfasis en Triatominae y Phlebotominae. IRD, UMR CNRS-IRD 9226. (Disponible en: http://www.mpl.ird.fr/morphometrics/).

15. Dvorak, V; Aytekin, AM; Alten, B; Skarupova, S; Votypka, J; Volf, P. 2006. A comparison of the intraspecific variability of Phlebotomus sergenti Parrot, 1917 (Diptera: Psychodidae). J. Vector. Ecol. 31: 229-238.

16. FAO. 2007. Panela production as a strategy for diversifying incomes in rural area of latin America. Rome.

17. Gallego, JL; Ríos, G; Giraldo, MJ. 1996. El Cultivo de la Caña Panelera en zona cafetera. Boletín divulgativo $\mathrm{N}^{\circ} 3$. CORPOICA, ASOPANELA. Manizales, Colombia.

18. Gómez, LA; Vargas GA. 2014. Los barrenadores de la caña de azúcar, Diatraea spp, en el valle del Río Cauca: Investigación participativa con énfasis en control biológico. CENICAÑA, Santiago de Cali, Valle del Cauca, Colombia. 
19. Jaramillo, ND; Wolff, CM. 2002. Geometric Morphometric differences between Panstrongylus geniculatus from field and laboratory. Mem. Inst. Oswaldo Cruz 97: 667-673.

20. Jaramillo, N. 2011. Morfometría geométrica: principios teóricos y métodos de empleo. Capítulo de libro. Universidad de Antioquía.

21. Lau, C; Jarvis, A; Ramírez, J. 2011. Agricultura colombiana: Adaptación al cambio climático. CIAT Políticas en Síntesis no. 1. Centro Internacional de Agricultura Tropical (CIAT), Cali, Colombia. 4 p.

22. Linares, B; Bastidas, R. 1996. Descripción comparativa del género Diatraea Guilding (Lepidoptera: pyralidae) que atacan la caña de azúcar en Venezuela. FONIAP. P92. Serie a $\mathrm{N}^{\circ} 11$.

23. Matías, A; De La Riva, JX; Torrez, M; Dujardin, JP. 2001. Rhodnius robustus in Bolivia Identified by its Wings. Mem. Inst. Oswaldo. Cruz 96: 947-950.

24. Parody, BP. 2011. Caracterización espacial y temporal de la estructura genética del primer insecto blanco del maíz transgénico Bt en Argentina, el barrenador Diatraea saccharalis (Fabricius). Tesis Doctoral. Facultad de Ciencias Exactas y Naturales. Universidad de Buenos Aires. Buenos Aires, Argentina.

25. Pastrana, C. 1991. Determinacion del ciclo de vida de Diatraea saccharalis y Diatraea indigenella bajo regímenes alimenticios y su comparación morfológica. Tesis de pregrado. Palmira, Valle Universidad Nacional de Colombia.

26. Pérez, EF; Martínez, KS. 2011. Distribución espacial y ciclo de vida de Diatraea spp. En plantaciones de Saccharum officinarum (Caquetá, Colombia). Ingeniería y Amazonía 4(2). Universidad de la Amazonía. Amazonas. Colombia. 
27. Rohlf, F; Marcus, L. 1993. A revolution in morphometrics. Trends Ecol Evol. 8:12932.

28. Rohlf, F; Slice, D. 1990. Extensions of the Procrustes method for the optimal superimposition of landmarks. Syst Zool.39:40-59.

29. Rubio-Pallis, Y. 1998. Caracterización morfométrica de poblaciones de Anopheles (Nyssorhynchus) darlingi del sur de Venezuela. Boletín entomología venezolana $13: 141-172$.

30. Schachter-Broide, J; Dujardin, JP; Kitron, U; Gurtler, R. 2004. Spatial structuring of Triatoma infestans (Hemiptera, Reduviidae) populations from Northwestern Argentina using wing geometric Morphometry. J. Med. Entomol. 41: 643-649.

31. Shi, J; Chen, F; Melody, K. 2015. Differences in Wing Morphometrics of Lymantria dispar (Lepidoptera: Erebidae) Between Populations That Vary in Female Flight Capability. Ann. Entomol. Soc. Am. 1-8.

32. Sontigun, N; Sukontason, K; Zajac, B; Zehner, R; Sukontason, K; Wannasan, A; Amendt, J. 2017. Wing morphometrics as a tool in species identification of forensically important blow flies of Thailand. Parasites \& Vectors. 10:229

33. Soto-Vivas, A; Liria, J; De Luna, E. 2011. Morfometría geométrica y filogenia en Rhodniini (Hemiptera, Reduviidae) de Venezuela. Acta Zool. Mex. 27: 87-102.

34. Vargas, G; Lastra, LA; Solis MA. 2013. First record of Diatraea tabernella (Lepidoptera: crambidae) in the Cauca river valley of Colombia. Florida Entomologist, 96(3):1198-1201.

35. Vargas, G; Lastra, LA; Villegas, A; Barco LE. 2013. Diatraea tabernella: Nueva especie de barrenador del tallo en el valle del río Cauca. Importancia y perspectivas de manejo. Cali. CENICAÑA. 4p. (Serie divulgativa $\mathrm{N}^{\circ} 16$ ). 
36. Vázquez, L. 2011. Cambio climático, incidencia de plagas y prácticas agroecológicas resilientes. Instituto de investigaciones de sanidad vegetal, la habana. En: Innovación agroecológica, adaptación y mitigación del cambio climático. Instituto Nacional de Ciencias Agrícolas (INCA). La Habana. 2011. 242p. ISBN 978-959-7023-53-1.

37. Villegas, J; Feliciangeli, MD; Dujardin JP. 2002. Wing shape divergence between Rhodnius prolixus from Cojedes (Venezuela) and Rhodnius robustus from Mérida (Venezuela). Infect. Genet. Evol. 2: 121-128. 